was due to the explosion of an artificial "alien body", and involved nuclear reactions. Within the apparently monolithic structure of Soviet scientific publishing, its appearance, however, is startling.

There have been a number of expeditions to the Tungus area in recent years. Detailed analyses of soil and peat samples have been made, revealing, inter alia, a large quantity of silicate particles (diameter less than $200 \mu \mathrm{m}$ ) in the 1908 peat layers near the epicentre. Last March, Professor Emlen V. Subbotovich, the geophysicist, announced the findings of these expeditions: all previous theories, he said, including anti-matter, meteorite, or alien spacecraft, were wrong. The explosion was caused by a cometlike body, with density not greater than $0.9 \mathrm{~g} \mathrm{~cm}^{-2}$. His pronouncement was made with all the concomitants of a definitive pronouncement. Where, then does Zolotov's theory fit in?

Last week, a former member of several Tungus expeditions visited London-Dr Khronid Lyubarskii, who was recently exiled for his part in the dissident human-rights campaign. $\mathrm{Dr}$ Lyubarskii, an astrophysicist specialising in the physics of meteors and meteorites, fully endorsed the official view that a comet was responsible for the Tungus event. According to him, Zolotov, who was described in the broadcast as a mathematician and physicist, was originally an engineer from an oil prospecting team. How he first became involved with Tungus is not clear; the impression which Dr Lyubarskii gave of him is, however, a familiar one-the self-appointed "expert" who in his own opinion knows far more than the scientist in the field Zolotov's article, it turns out, did not appear in any scientific journal; hence no "certificate" was needed. It was published in the monthly Turist-perhaps in the hope of attracting holidaymakers into the further reaches of Siberia. And for popular journals, explained Dr Lyubarskii, while there is strict political censorship, there is no control of "scientific" (or pseudoscientific) content.

It is perhaps inevitable that genuine scientific research is surrounded by a penumbra of more or less wild speculation; indeed, this may be a necessary factor in the growth of science. One of the dangers of a monolithic statecontrolled scientific establishment is that the rigid structure of the system can exclude the brilliant amateur, and also the scientist trained in one discipline, who, like Pasteur, does his most significant work in another. However wild Zolotov's theory, the fact that it can still find an official outlet in the Soviet Union is a happy omen.

Vera Rich
For years, many adult middle-class males have tried to substitute diet for exercise in warding off heart attacks. The research effort on this "diet-andheart" question, says George Mann, "has ended in disarray." Dr Mann's conclusions were noted in Nature (3 November, page 2) by Dr Rivers.

The popular dogma, which dates from around 1950, has said that diets low in saturated fats and cholesterol, but containing polyunsaturated fats (PUFAs), will produce lower bloodcholesterol levels and will lessen the risk of coronary heart disease. The idea was well-accepted; it was supported by many prominent clinicians and nutritionists. Sales of vegetable oils grew apace, especially those oils for which a slightly higher-thanaverage content of esters of essential PUFAs could be claimed. Big fields of thistle-like safflowers yellowed the landscape with their blossoms. Safflower seeds furnished the cordon bleu of vegetable oils, so rich in PUFAs that you could just feel it doing you good. The oil was hydrogenated to make margarine, even though, as George Mann points out, the hydrogenated, and hence trans, fatty acids have a hypercholesteremic effect. Butter, cream and eggs were to be shunned.

What was the effect of 25 years of these measures? By 1977, as Dr Mann points out, the results show that "a huge cohort of persons past middle age has been recruited to a futile regimen of dietary restrictions". No diet therapy has been shown effective for the prevention or treatment of coronary heart disease. Two of five dietary regimes in which vegetable oils were featured showed an increased incidence of deaths from cancer in the treated groups.

This may be meaningless, but several experiments have shown an increase in tumour incidence in rats on diets high in polyunsaturated fats,

\section{Sursum corda}

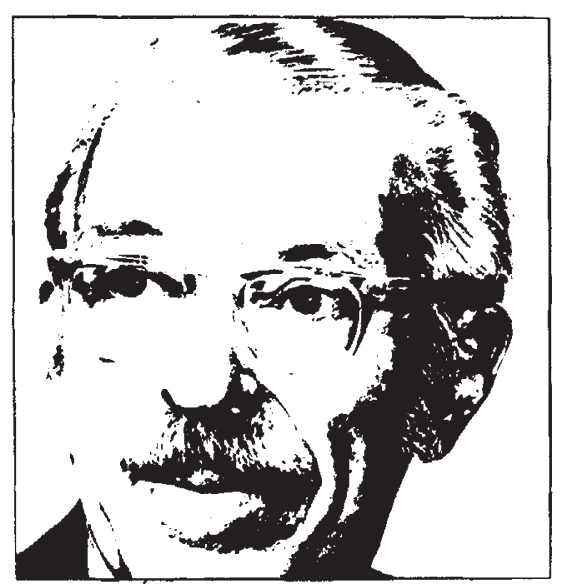

\section{THOMAS H. JUKES}

such as sunflower-seed oil and corn oil, as compared with saturated fats.

The vegetable oil motif was for many years the official guide to cooking and eating. Who would dare to challenge the sonorous pronouncements of medical authorities when the punishment for such heresy was incapacitation or death? We could almost feel the waxy cholesterol and tallowy fats clinging to our arterial walls after we suicidally wolfed down scrambled eggs or lamb chops. Thoughtful, health-oriented advertise- ments gave us tasty recipes, made with vegetable oils. Sugar was added to the list of culprits; it could allegedly give rise to "hard fats" when metabolised. In any case, sugar is sweet, and therefore, sinful.

A new ascetism burgeoned and, true to type, its main objective is restoring sybaritic evil-doers to the path of dietary righteousness. Its leader is Senator George McGovern, whose committee on 'Nutrition and human needs' has issued a preposterous report on 'Dietary goals' which calls for governmental action to implement the prejudices of its writers.

The report says, among other things, that it is necessary [sic] to make partial substitution of polyunsaturated fat for saturated fat. Why? What about the rats with cancer? The report quotes the New York Times to support its thesis for reducing sugar consumption by about $40 \%$, and speaks ominously of cola-guzzling youngsters (the little devils!) and the need for protection against "hidden sugar". Martini-guzzling adults get off without reprimand or umbrage, but we are told that monosodium glutamate "may be associated with headaches, flushes in the head and body and tingling in the spine". Since most common vegetable food proteins contain $20 \%$ or more of glutamate, there should be much tingling after a meal, and don't blame the martinis.

Avast to McGovern and his anonymous bluenoses! 'Tis the season to be jolly! I don't think they know what they're talking about, anyway, even if they have wangled a multimillion dollar appropriation to brainwash the public. 